\title{
Antimicrobial resistance of Neisseria gonorrhoeae isolates from the Stuttgart and Heidelberg areas of Southern Germany
}

\author{
M. Enders • A. Turnwald-Maschler $\cdot$ T. Regnath
}

Published online: 30 May 2006

(C) Springer-Verlag 2006

Eur J Clin Microbiol Infect Dis (2006) 25:318-322

Due to a typesetting error, the symbols $\geq$ and $\leq$ appeared incorrectly as $>$ and $<$, respectively, throughout the text.

The online version of the original article can be found at: http://dx.doi. org/10.1007/s10096-006-0134-y

M. Enders $(\bowtie) \cdot$ T. Regnath

Labor Enders und Partner, Institut für Virologie,

Infektiologie und Epidemiologie e.V.,

Rosenbergstrasse 85,

70193 Stuttgart, Germany

e-mail: menders@labor-enders.de

A. Turnwald-Maschler

Department of Microbiology and Hygiene,

Laboratory Group Limbach 69126 Heidelberg, Germany 